\title{
Correction to: An Alternative Explanation for Difficulties with Speech in Background Talkers: Abnormal Fusion of Vowels Across Fundamental Frequency and Ears
}

\author{
Lina A. J. Reiss ${ }^{1}$, and Michelle R. Molis ${ }^{1,2}$ \\ ${ }^{1}$ Department of Otolaryngology, Oregon Health and Science University, 3181 SW Sam Jackson Park Road, \\ Portland, OR 97239, USA \\ ${ }^{2}$ National Center for Rehabilitative Auditory Research, VA Portland Health Care System, 3710 SW US Veterans \\ Road, Portland, OR 97239, USA \\ Online publication: 16 July 2021
}

\section{Correction to: Journal of the Association for Research in Otolaryngology https://doi.org/10.1007/s10162-021-00790-7}

This article was updated to correct the author affiliations, the labeling in Figure 10, and the Acknowledgments.

Publisher's Note Springer Nature remains neutral with regard to jurisdictional claims in published maps and institutional affiliations. 